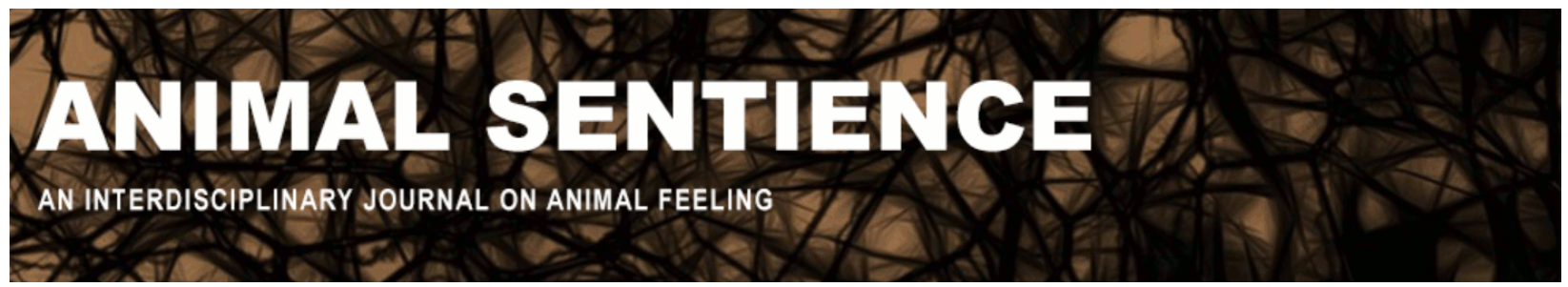

Spiegel, Rainer (2019) Non-human animals providing rescue in medical emergencies. Animal Sentience 23(23)

DOI: $10.51291 / 2377-7478.1400$

Date of submission: 2019-02-04

Date of acceptance: 2019-02-18 (c) 


\title{
Non-human animals providing rescue in medical emergencies
}

\author{
Commentary on Chapman \& Huffman on Human Difference
}

\author{
Rainer Spiegel \\ Department of Anesthesiology, Intensive Care and Pain Management \\ BG Trauma Center \\ University of Tuebingen, Germany
}

\begin{abstract}
In their target article, Chapman \& Huffman challenge the quotation of Sir William Osler that the desire to take medication distinguishes humans from non-human animals. They provide examples of self-medication in non-human animals. Based on these examples, it can be inferred that non-human animals practice at least some form of medicine for symptom control. I would like to extend this view by showing that non-human animals not only provide self-medication, but also rescue others facing emergencies.
\end{abstract}

Rainer Spiegel, M.D. (University of Munich), Ph.D. in Psychology (University of Cambridge), is a specialist in internal medicine with an interest in emergency medicine. He witnessed cases where behavior of non-human animals elicited emergency calls, which ultimately saved lives. Website

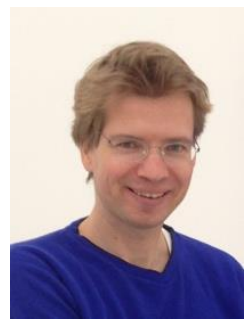

Chapman \& Huffman (2018) (C \& H) argue against the opinion shared by many scholars who consider humans superior to non-human animals. They challenge arguments provided by those scholars and give counter-examples. In addition, they refer to cognitive tasks where young chimpanzees outperform adult humans (Inoue \& Matsuzawa, 2007). Being a medical doctor, I would first like to comment on the examples of self-medication by non-human animals. Subsequently, I will provide additional examples from the behavior of non-human animals in natural disasters and medical emergencies.

C \& H cite the Canadian physician Sir William Osler in his famous quote: "A desire to take medicine is, perhaps, the great feature which distinguishes man from other animals." Based on evidence provided by Engel (2002), Huffman et al. (1997), and Huffman (2007), they subsequently refute Sir William Osler's notion. They demonstrate that self-medication takes place among several non-human animals, including elephants, snow geese, ants and chimpanzees, who make use of plants for symptom control. Some people may argue that eating plants is very different from the medication taken by humans, which these people may consider a more sophisticated form of medication. In spite of these differences, one has to consider that the way some humans take medication may even be harmful: I once had a patient with an anaphylactic shock after he took left-over antibiotic drugs that were originally prescribed for his sister. His intention to swallow the antibiotics was his belief that they would help against the common cold from which he was suffering. A lot of other examples could be added here. 
Obviously, humans and non-human animals differ in their skills and behavior. Their skills are often adapted to the environment they live in. Assessing a non-human animal with a task created by a human is certainly not a fair test. Following C \& H or Inoue and Matsuzawa (2007), there are tasks originally created by humans, however, that non-human animals can do better than humans. Here I would like to add an example with regard to natural disasters. In the 2004 Tsunami following an earthquake off the coast of Sumatra in the Indian Ocean, humans did not foresee the consequences of their actions. For example, when water receded from the coast just prior to the waves, many tourists went towards the sea. They did not realize the catastrophic consequences. This was probably because they were not used to tsunamis and not prepared for this situation. A large number of non-human animals, particularly elephants, survived the tsunami because they had moved inland (Garstang, 2009). The interpretation provided by Garstang (2009) included cognitive capabilities of elephants similar to the ones described by Bates et al. (2008). According to these cognitive capabilities, elephants were able to draw deductions based on signals they perceived in their environment.

Concerning medical emergencies, I will list a few examples where non-human animals have rescued others. In the first two examples, non-human animals provided help to humans, followed by two examples where non-human animals rescued each other. The first example concerns seizure-alerting dogs. While there is debate between experts whether dogs can actually predict a seizure, there is agreement that a dog's ability to organize help could be life-saving for the person who is experiencing the seizure (Doherty \& Haltiner, 2007).

Sceptics might argue that these dogs were specifically trained for that purpose. There are, however, situations that make specific training unlikely. For example, a video posted by the BBC shows how a little boy who cycled in front of his family's home was rescued by the family cat. In this video, the cat attacked a pitbull in the process of pulling the boy off his bicycle (BBC News covering CCTV footage from May 13, 2014).

The next example is from my personal experience. The dog of an unconscious person who was later brought to the Emergency Department did not stop barking until people were alarmed and organized rescue for the dog's owner. Sceptics may still argue that the dog barked for another reason. Similarly, they may say that the behavior of non-human first aiders clearly differs from human first aiders. When one deducts the limited resources that non-human animals have to organize help in these situations, however, one undoubtedly has to recognize their contributions.

The next two examples are from personal experience of my family. In these examples, non-human animals rescued each other in emergency situations. When a cat caught a bird, another bird flew towards the cat with a shock-landing on the cat's back. The cat appeared so confused that both birds managed to fly away. Another example stems from an unconscious chipmunk after having been hurt by a rock. Other chipmunks rescued the injured chipmunk out of the danger zone and pulled the chipmunk into a hollow.

In summary, different humans and different non-human animals are unique in their behavior and all deserve our full respect. When it comes to emergencies, there are probably more similarities between humans and non-human animals than previously assumed. 


\section{References}

Bates, L. A., Poole, J. H., \& Byrne, R. W. (2008) Elephant cognition. Current Biology, 18(13), R544546.

Chapman, C. A., \& Huffman, M. A. (2018) Why do we want to think humans are different? Animal Sentience, 163, 1-8.

Doherty, M. J., \& Haltiner, A. M. (2007) Wag the dog: skepticism on seizure alert canines. Neurology, 68(4), 309.

Engel, C. (2002) Wild health. Boston: Houghton Mifflin.

Garstang, M. (2009) Precursor tsunami signals detected by elephants. The Open Conservation Biology Journal, 3, 1-3.

Huffman, M. A. (2007) Primate self-medication. In Primates in perspective (C. J. Campbell, A. Fuentes, K. C. MacKinnon, M. Panger, \& S. K. Bearder, Eds.), pp. 677-690. Oxford: Oxford University Press.

Huffman, M. A., Gotoh, S., Turner, L. A., Hamai, M., \& Yoshida, K. (1997) Seasonal trends in intestinal nematode infection and medicinal plant use among chimpanzees in the Mahale Mountains, Tanzania. Primates, 38(2), 111-125.

Inoue, S., \& Matsuzawa, T. (2007) Working memory of numerals in chimpanzees. Current Biology, 17(23), R1004-R1005. 